\title{
Accidental exposure (AE) to peanut in a large cohort of Canadian children with peanut allergy
}

\author{
Sabrine Cherkaoui ${ }^{1 *}$, Moshe Ben-Shoshan ${ }^{2}$, Reza Alizadehfar ${ }^{2}$, Yuka Asai $^{3}$, Greg Shand ${ }^{4}$, Yvan St-Pierre $^{4}$, \\ Laurie Harada ${ }^{5}$, Mary Allen ${ }^{6}$, Ann Clarke ${ }^{4,7}$ \\ From Canadian Society of Allergy and Clinical Immunology Annual Scientific Meeting 2013 \\ Toronto, Canada. 3-6 October 2013
}

\section{Background}

We have previously estimated that the annual rate of accidental exposure (AE) to peanut in a Canadian cohort of 1411 children with peanut allergy, followed for 2227 patient-years, was $11.9 \%$ [1]. The cohort has increased to 1825 children, with 4134 patient-years of follow-up, and we determined the incidence of AE in this expanded cohort and described the severity, management, and location of the AE.

\section{Methods}

Children with physician-confirmed peanut allergy were identified from the Montreal Children's Hospital and food allergy advocacy organizations from 2004 to May 2013. Parents completed a questionnaire at study entry and every two years regarding their child's $\mathrm{AE}$ to peanut over the preceding year; starting in 2010, follow-up questionnaires were administered annually.

\section{Result}

The mean age (SD) was 2.4 (2.1) years at diagnosis and 7.0 (4.0) years at the time of the initial questionnaire completion. Patients were predominantly boys $(61.8 \%)$ and Caucasians (89.5\%). When all children were included, regardless of length of observation interval, $456 \mathrm{AE}$ occurred in 336 children over 4134 patient-years, yielding an annual incidence rate of $11.0 \%$ (95 \% CI, 9.0 - 13.1\%). Because the rate of AE may vary with observation interval length, the rate was calculated excluding $\mathrm{AE}$ occurring after the initial questionnaire and excluding those providing $<1$ year of observation; this yielded $164 \mathrm{AE}$ in 141 children over 1405 patient-years, for an annual

\footnotetext{
* Correspondence: sabrine.cherkaoui@umontreal.ca

'Division of Internal Medicine, Department of Medicine, University of

Montreal, Montreal, QC, Canada

Full list of author information is available at the end of the article
}

incidence rate of $11.7 \%$ (95\% CI, $9.7 \%-13.6 \%$ ). One hundred forty-seven $\mathrm{AE}$ were mild, 242 moderate, and 67 severe. Among 429 AE preceded by an initial reaction, $22.4 \%$ of $\mathrm{AE}$ were more severe than the initial reaction. No treatment was administered for 41 (27.9\%) mild AE, $40(16.5 \%)$ moderate and $4(6.0 \%)$ severe. Of $309 \mathrm{AE}$ that were moderate/severe, only 93 (30.1\%) sought medical attention and among these, only $30.1 \%$ received epinephrine. Of the 153 moderate/severe AE treated at home, only (11.8\%) received epinephrine. Thirty-nine percent of AE occurred at home, $17.3 \%$ at relatives/friends' home, $11.4 \%$ in restaurants, $7.5 \%$ at schools/day-cares prohibiting peanut, $3.7 \%$ at schools/day-cares allowing peanuts, and $20.6 \%$ at other or unknown places.

\section{Conclusion}

Despite increasing efforts to provide information on the management of food allergy, $\mathrm{AE}$ continue to occur, mainly in the child's home but also in peanut free schools/ day-cares. Most moderate/severe AE are managed inappropriately by caregivers and physicians. Consequently, more education is required on the importance of strict allergen avoidance and the need for prompt and correct management of anaphylaxis.

\footnotetext{
Authors' details

${ }^{1}$ Division of Internal Medicine, Department of Medicine, University of Montreal, Montreal, QC, Canada. ${ }^{2}$ Division of Pediatric Allergy and Clinical Immunology, Department of Pediatrics, McGill University Health Center, Montreal, QC, Canada. ${ }^{3}$ Division of Dermatology, Department of Medicine, McGill University Health Center, Montreal, QC, Canada. ${ }^{4}$ Division of Clinical Epidemiology, Department of Medicine, McGill University Health Center, Montreal, QC, Canada. ${ }^{5}$ Anaphylaxis Canada (AC), Toronto, ON, Canada. ${ }^{6}$ Allergy/Asthma Information Association (AAIA), Toronto, ON, Canada. ${ }^{7}$ Division of Clinical Immunology and Allergy, Department of Medicine, McGill University Health Center, Montreal, QC, Canada.
} 


\section{Reference}

1. Nguyen-Luu, Ben-Shoshan, Clarke : Inadvertent exposures in children with peanut allergy. Pediatric Allergy and Immunology 2012, 23(2):133-9.

doi:10.1186/1710-1492-10-S1-A32

Cite this article as: Cherkaoui et al: Accidental exposure (AE) to peanut

in a large cohort of Canadian children with peanut allergy. Allergy,

Asthma \& Clinical Immunology 2014 10(Suppl 1):A32.

Submit your next manuscript to BioMed Central and take full advantage of:

- Convenient online submission

- Thorough peer review

- No space constraints or color figure charges

- Immediate publication on acceptance

- Inclusion in PubMed, CAS, Scopus and Google Scholar

- Research which is freely available for redistribution

Submit your manuscript at www.biomedcentral.com/submit
() Biomed Central 